\title{
Risk of dementia in parents of probands with and without the apolipoprotein E4 allele. The EVA study
}

\author{
S Danet, T Brousseau, F Richard, P Amouyel, C Berr, for the EVA Study Group
}

\begin{abstract}
Study objective-Age, family history of dementia and the 84 allele of the apolipoprotein $E$ gene have been associated with Alzheimer's disease (AD). Considering the strength of APOE- $\varepsilon 4$ as a genetic risk factor for $\mathrm{AD}$, this factor might explain a large part of the association between $\mathrm{AD}$ and a family history of dementia. Therefore, in the general population, a higher frequency of dementia should be observed among parents of probands with at least one $\varepsilon 4$ allele than in parents of probands without this allele.

Design, setting, and participants-The study investigated a sample of 1153 volunteers between 59 and 71 years old, genotyped for the APOE gene, all participating in the EVA study. Dementia in their parents was determined using a self reported questionnaire.

Main results-The frequency of dementia in 2164 parents was examined and it was found that 245 were demented. The percentage of demented parents was $13.0 \%$ in the subgroup of parents of subjects having one or two $\varepsilon 4$ alleles and $10.8 \%$ in the other subgroup. The relative risk of dementia among parents according to the APOE- 84 status of probands, was calculated using a Cox model adjusted for the educational level of parents and their history of stroke: $\mathrm{RR}=1.21(95 \% \mathrm{CI} 0.90,1.63)$.

Conclusion-This lack of association supports the observation that in the general population, APOE- 84 cannot explain a large part of family history of dementia. (F Epidemiol Community Health 1999;53:393-398)
\end{abstract}

Epidémiologiques en

Neurologie et

Psychopathologie,

Paris, France

$S$ Danet

C Berr

INSERM U508,

Service

d'Epidémiologie et de

Santé Publique,

Institut Pasteur de

Lille, France

$\mathrm{T}$ Brousseau

F Richard

P Amouyel

Correspondence to: Dr C Berr, INSERM U360,

Hôpital La Salpêtrière,

75651 Paris Cedex 13,

France.

Accepted for publication 15 January 1999 with dementia compared with $12 \%$ to $36 \%$ in relatives of controls. ${ }^{2}$ Considering the strength of the APOE- $\varepsilon 4$ allele as a genetic risk factor for $\mathrm{AD}$, this factor might explain a large part of the association between a family history of dementia and $\mathrm{AD}$. Whether the risk of $\mathrm{AD}$ associated with APOE- $\varepsilon 4$ allele may be modified by a family history of dementia is still controversial. Li et al have found that the cumulative risk for dementia in relatives of $\mathrm{AD}$ probands with and without the $\varepsilon 4$ allele was significantly higher than in relatives of nondemented controls. The increase in rate of dementia in relatives of $\mathrm{AD}$ probands compared with controls was independent of the $\varepsilon 4$ status of AD probands. ${ }^{20}$ Duara et al have found that $\varepsilon 4$-positive $\mathrm{AD}$ patients tend to have an higher rate of family history of dementia than $\varepsilon 4$-negative $\mathrm{AD}$ patients ( $58 \%$ versus $40 \% ; \mathrm{p}=$ $0.02) .{ }^{21}$ Van Djuin et al and Zubenko et al have shown a stronger association between $\mathrm{AD}$ and the $\varepsilon 4$ allele, in the presence of a family history of dementia. ${ }^{223}$ On the other hand, Mayeux et al have described a positive association between $\mathrm{AD}$ and the $\varepsilon 4$ allele in the absence of a family history of dementia. ${ }^{24}$ Only one prospective study has examined in the oldest elderly the risk of AD in relation to both a family history of dementia and the APOE- $\varepsilon 4$ status. ${ }^{25}$ Unfortunately, few subjects had both risk factors and that study was inconclusive whether the age specific risk for $\mathrm{AD}$ according to the $\varepsilon 4$ allele is modified by a family history of dementia.

No study has been conducted yet in the general population and the frequencies of family history of dementia according to the APOE genotypes remain unknown. Moreover, under the assumption that the APOE- $\varepsilon 4$ explains a large part of the association between $\mathrm{AD}$ and family history of dementia, we should discover in the general population, a higher frequency of dementia in parents of probands with this allele than in parents of probands without this allele. In particular, the risk of dementia in parents according to the status of probands for the $\varepsilon 4$ allele, should be close to the ratio of probabilities for parents to have at least one APOE- $\varepsilon 4$ allele in the two groups of parents. To test this hypothesis, we have examined in a sample of 1153 volunteers, aged 59-71 years with high cognitive performances and genotyped for the apolipoprotein E gene, the history of dementia in their parents.

\section{Methods}

The EVA study is a longitudinal study on vascular and cognitive aging. Details of the study 


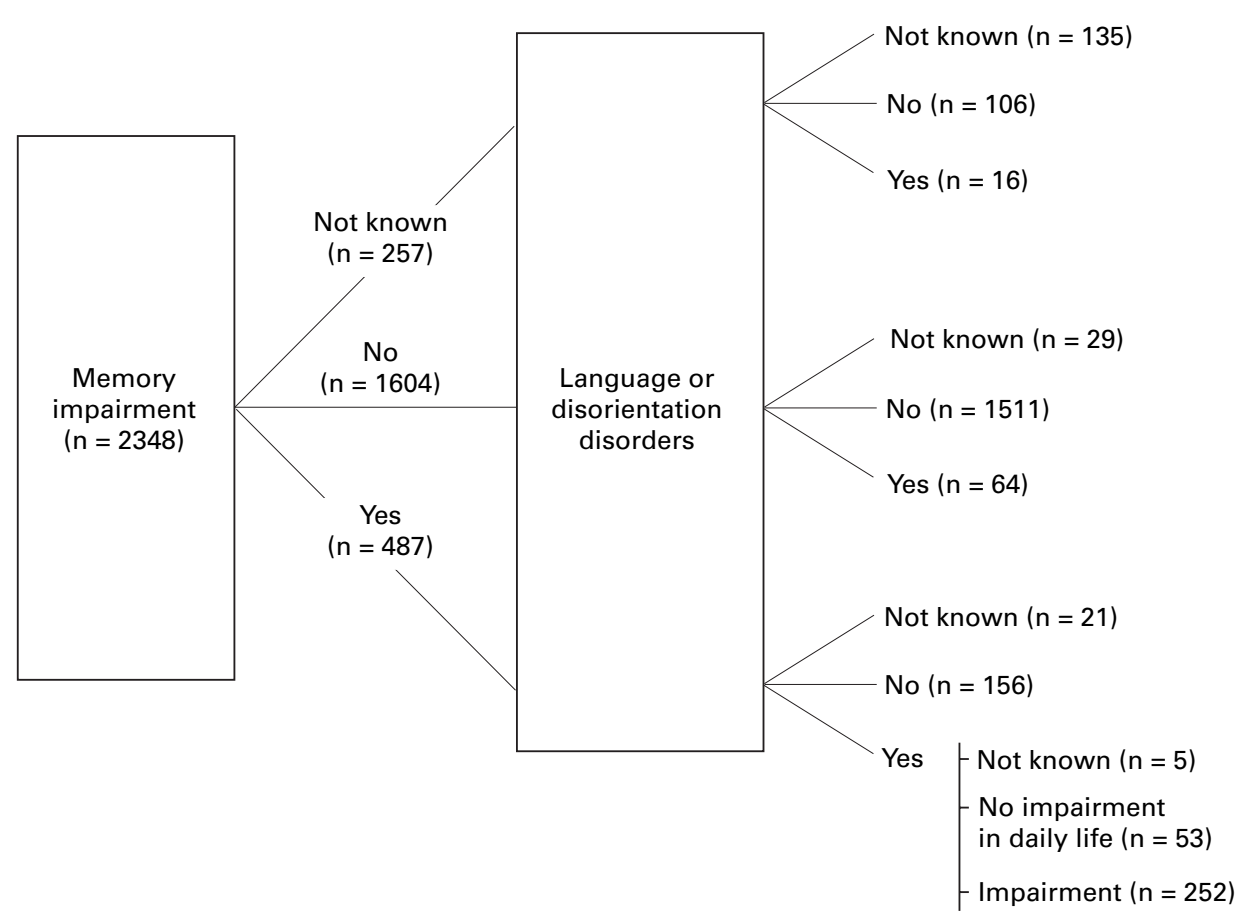

Figure 1 Decision tree for the identification of parental status for dementia according DSMIII-R criteria.

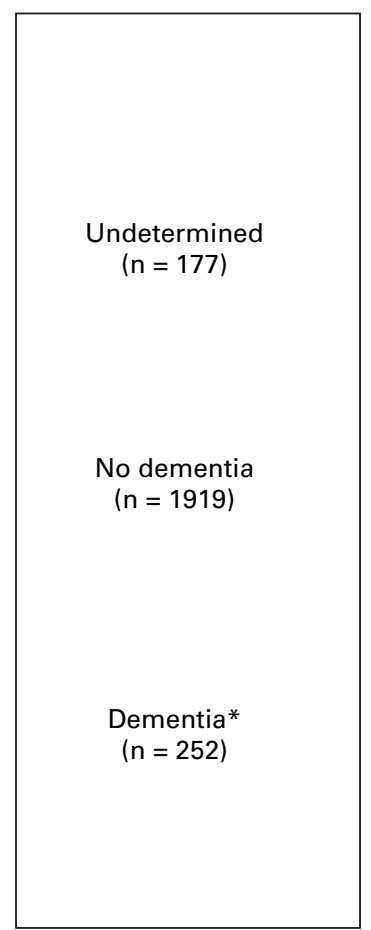

* 7 parents with history of depression were recoded as "undetermined" after this identification. design have been described elsewhere. ${ }^{26}$ The study population is composed of volunteers born between 1922 and 1932, who were recruited from the electoral rolls of the city of Nantes (western France). When a subject was recruited, their spouse was systematically asked to participate in the study if they were in the required age range. Between June 1991 and July 1993, 1389 subjects were enrolled in the study. All subjects provided their informed consent, and the study design was approved by the ethical committee of the University Hospital of Bicêtre.

PERSONAL DATA

The baseline visit took place between June 1991 and July 1993. Data on patient background, educational achievement, present and past medical history were collected using a standardised questionnaire during a face to face interview. The examination included the Mini Mental State Examination (MMSE), which assessed various cognitive skills.

GENOMIC DNA

In the second part of the EVA study, conducted between July 1993 and June 1995, 1200 subjects agreed to participate in genetic testing with genomic DNA available on 1174. A specific informed consent was signed by the participants and a specific approval was given by the ethical committee. Genomic DNA was prepared from white blood cells and genotyping was performed with a restriction fragment length polymorphism. The APOE sequence containing codon positions 112 and 158 , at the origin of the polymorphism, was amplified.
The amplified products were digested with Hha I and subjected on polyacrylamide gels. ${ }^{27}$ All gel results for APOE genotyping were analysed by two different investigators.

DATA ABOUT PARENTS, CRITERIA FOR DEMENTIA Detailed data concerning their parents were obtained from the EVA volunteers with self reported standardised questionnaires, at the entry in the study. The two questionnaires, one for the mother and the other one for the father, included specific questions designed to search for memory impairment, language and disorientation troubles, loss of autonomy, history of depression and stroke. Age of parent is age at death or current age if they were alive at the time of the study. The educational level of parents was recorded in two groups ( $<7$ years of schooling and $\geqslant 7$ years).

Figure 1 describes the decision tree for the identification of the parental status for dementia according to DSMIII-R criteria. ${ }^{28}$ To have a dementia, a parent had to meet the three following criteria: (1) memory impairment, (2) language trouble and/or disorientation, (3) one or more of these disorders had to be sufficiently severe to interfere with social or occupational

Table 1 Allele frequencies for apolipoprotein $E$ gene $(n=1153)$

\begin{tabular}{lll}
\hline APOE genotype & $(n)$ & Allele frequencies \\
\hline APOE $(\varepsilon 2 \varepsilon 2)$ & $(3)$ & APOE- $\varepsilon 2=0.067$ \\
APOE $(\varepsilon 2 \varepsilon 3)$ & $(131)$ & \\
APOE $(\varepsilon 2 \varepsilon 4)$ & $(17)$ & APOE- $\varepsilon 3=0.809$ \\
APOE $(\varepsilon 3 \varepsilon 3)$ & $(754)$ & \\
APOE $(\varepsilon 3 \varepsilon 4)$ & $(227)$ & APOE- $\varepsilon 4=0.124$ \\
APOE $(\varepsilon 4 \varepsilon 4)$ & $(21)$ & \\
\hline
\end{tabular}


Table 2 Characteristics of probands according to the status for dementia in parents

\begin{tabular}{llll}
\hline & $\begin{array}{l}\text { Demented parents } \\
(n=245)\end{array}$ & $\begin{array}{l}\text { Non-demented parents } \\
(n=1919)\end{array}$ & $p$ \\
\hline Sex of proband \% women & 61.5 & 57.3 & NS \\
Age of proband (y (SD)) & $64.7(3.0)$ & $65.0(2.9)$ & NS \\
Educational level of proband & 31.0 & 30.5 & \\
$\quad$ 5 years (\%) & 18.0 & 18.4 & NS \\
6-9 years (\%) & 32.2 & 36.4 & \\
10-12 years (\%) & 18.8 & 14.7 & NS \\
$>12$ years (\%) & $28.2(1.9)$ & $28.2(2.1)$ & NS \\
MMSE score (mean (SD)) & 2.0 & 3.3 & \\
MMSE score below 24 (\%) & & & \\
\hline
\end{tabular}

Table 3 Rates of dementia by age, in mothers and fathers in the EVA study

\begin{tabular}{|c|c|c|c|c|}
\hline \multirow[b]{2}{*}{$\operatorname{Age}^{\star}(y)$} & \multicolumn{2}{|c|}{$\begin{array}{l}\text { Fathers }(n=1063) \\
\text { Rates of dementia }\end{array}$} & \multicolumn{2}{|c|}{$\begin{array}{l}\text { Mothers }(n=1101) \\
\text { Rates of dementia }\end{array}$} \\
\hline & $\%$ & $95 \% C I$ & $\%$ & $95 \% C I$ \\
\hline$<60$ & 1.5 & $0.04,3.0$ & 1.8 & $0.0,3.8$ \\
\hline $60-69$ & 4.3 & $0.01,7.3$ & 4.8 & $0.7,8.8$ \\
\hline $70-79$ & 8.7 & $5.5,12.0$ & 10.5 & $6.6,14.4$ \\
\hline $80-89$ & 10.8 & $7.1,14.5$ & 19.7 & $16.0,23.4$ \\
\hline$\geqslant 90$ & 19.0 & $9.4,28.7$ & 31.0 & $23.7,38.2$ \\
\hline
\end{tabular}

^Age of parent is age at death or current age if they were alive at the time of the study.

functioning. When a parent did not meet these criteria, they were classified as non-demented. The number of "undetermined" is the sum of: (a) parents with unknown status for memory impairment and language or disorientation disorders ( $n=135)$, (b) parents with language or disorientation disorders but unknown status for memory impairment $(n=16)$, (c) parents with memory impairment but unknown status for other symptoms $(n=21)$, (d) parents with memory impairment and language or disorientation disorders but unknown status for impairment in daily life $(n=5)$. Later on, demented parents for whom a history of depression was reported (five mothers and two fathers), were recoded as "undetermined".

Finally, among the 1174 subjects genotyped for APOE, the notion of dementia in parents was determined for 1101 mothers and 1063 fathers. The status was undetermined for both parents of 19 subjects and known in at least one parent for 1151 subjects.

We have considered separately mothers and fathers instead of a pair of parents, given the difficulty of summarising in a single variable personal characteristics that could widely differ in a pair of parents (age, educational level, history of stroke). Thus, we have compared two groups of parents: parents of probands with at least one $\varepsilon 4$ allele and parents of probands without this allele.
The probabilities for parents to have at least one $\varepsilon 4$ allele have been calculated under the Hardy-Weinberg equilibrium. If probands have no $\varepsilon 4$ allele, the probability for parents to have one $\varepsilon 4$ allele is estimated by the $\varepsilon 4$ allelic frequency in our sample. The probability is calculated from the formula proposed in appendix 1 in parents of probands with at least one $\varepsilon 4$ allele.

The Kaplan-Meier survival analysis method with one year intervals was used to estimate the cumulative risk of dementia among parents. We specified the age of parents, as defined previously, for the time variable. To analyse the differences between cumulative risk curves among parents, we used the log rank test. To take into account potential confounding factors recorded for parents, we have fitted a Cox proportional hazard model and the likelihood ratio has been used to test the various hypotheses. To check the proportional hazard model assumption, we used a graphic method. For all variables included in the model the log $(\log (\mathrm{S}(\mathrm{t})))$ plots were approximately parallel across strata. Differences between groups were assessed by one way analysis of variance or $\chi^{2}$ when appropriate. Statistical analyses were conducted with the Statistical Analysis System release $6.11 .^{29}$

\section{Results}

The population of this study included 487 men and 666 women $(n=1153)$. Mean age of subjects was $65.0(\mathrm{SD}=3.0)$ and mean MMSE score was $28.2(\mathrm{SD}=2.1)$. Thirty eight subjects $(3.3 \%)$ have a score below 24 at the MMSE. Allele frequencies for the apolipoprotein $\mathrm{E}$ gene are given in table 1: 265 subjects had at least one $\varepsilon 4$ allele and 888 no $\varepsilon 4$ allele. Only $21(1.8 \%)$ had the $\varepsilon 4 / \varepsilon 4$ genotype and no separate analysis of this genotype was made. The genotype distribution for APOE gene is in Hardy-Weinberg equilibrium. With the formula proposed in appendix 1, we have calculated the probabilities for parents to have at least one $\varepsilon 4$ allele according to the status for APOE- $\varepsilon 4$ allele of probands. Thus, the probability for parents to have at least one $\varepsilon 4$ allele is fivefold higher in parents of probands with at least one $\varepsilon 4$ allele $(p=0.59)$ than in parents of probands without this allele $(\mathrm{p}=0.12)$.

Status for dementia as defined, for 2164 parents was independent of sex, age, educational level and MMSE score of informants (table 2). Probands with missing data on dementia status in parents did not differ for sex, age, MMSE

Table 4 Characteristics of parents and history of stroke, by sex and status for dementia

\begin{tabular}{|c|c|c|c|c|c|c|}
\hline & \multicolumn{3}{|c|}{ Fathers $(n=1063)$} & \multicolumn{3}{|c|}{ Mothers $(n=1101)$} \\
\hline & Demented & Non-demented & $p$ & Demented & Non-demented & $p$ \\
\hline $\mathrm{Age}^{\star}$ & $\mathrm{n}=78$ & $\mathrm{n}=984$ & & $\mathrm{n}=167$ & $\mathrm{n}=934$ & \\
\hline Mean $(S D)$ & $78.6(10.8)$ & $69.1(15.4)$ & $10^{-4}$ & $84.4(7.9)$ & $74.5(15.8)$ & $10^{-4}$ \\
\hline Status at the time of the study & $\mathrm{n}=78$ & $\mathrm{n}=985$ & & $\mathrm{n}=167$ & $\mathrm{n}=934$ & \\
\hline$\%$ alive $(\mathrm{n})$ & $5.1(4)$ & $3.1(30)$ & - & $21.6(36)$ & $14.6(136)$ & 0.02 \\
\hline mean (SD) age of alive parents & $89.8(4.6)$ & $88.3(3.5)$ & - & $89.5(3.8)$ & $87.6(3.8)$ & 0.01 \\
\hline History of stroke & $\mathrm{n}=73$ & $\mathrm{n}=925$ & & $\mathrm{n}=151$ & $\mathrm{n}=889$ & \\
\hline$\%$ stroke & 63.0 & 17.4 & $10^{-3}$ & 43.1 & 20.1 & $10^{-3}$ \\
\hline Educational level & $\mathrm{n}=78$ & $\mathrm{n}=966$ & & $\mathrm{n}=164$ & $\mathrm{n}=918$ & \\
\hline$<7$ years $(\%)$ & 23.1 & 18.3 & NS & 31.7 & 23.1 & 0.02 \\
\hline
\end{tabular}

NS: not significant at $\mathrm{p}$ value $<0.05 .{ }^{\star}$ Age of parent is age at death or current age if they were alive at the time of the study. 


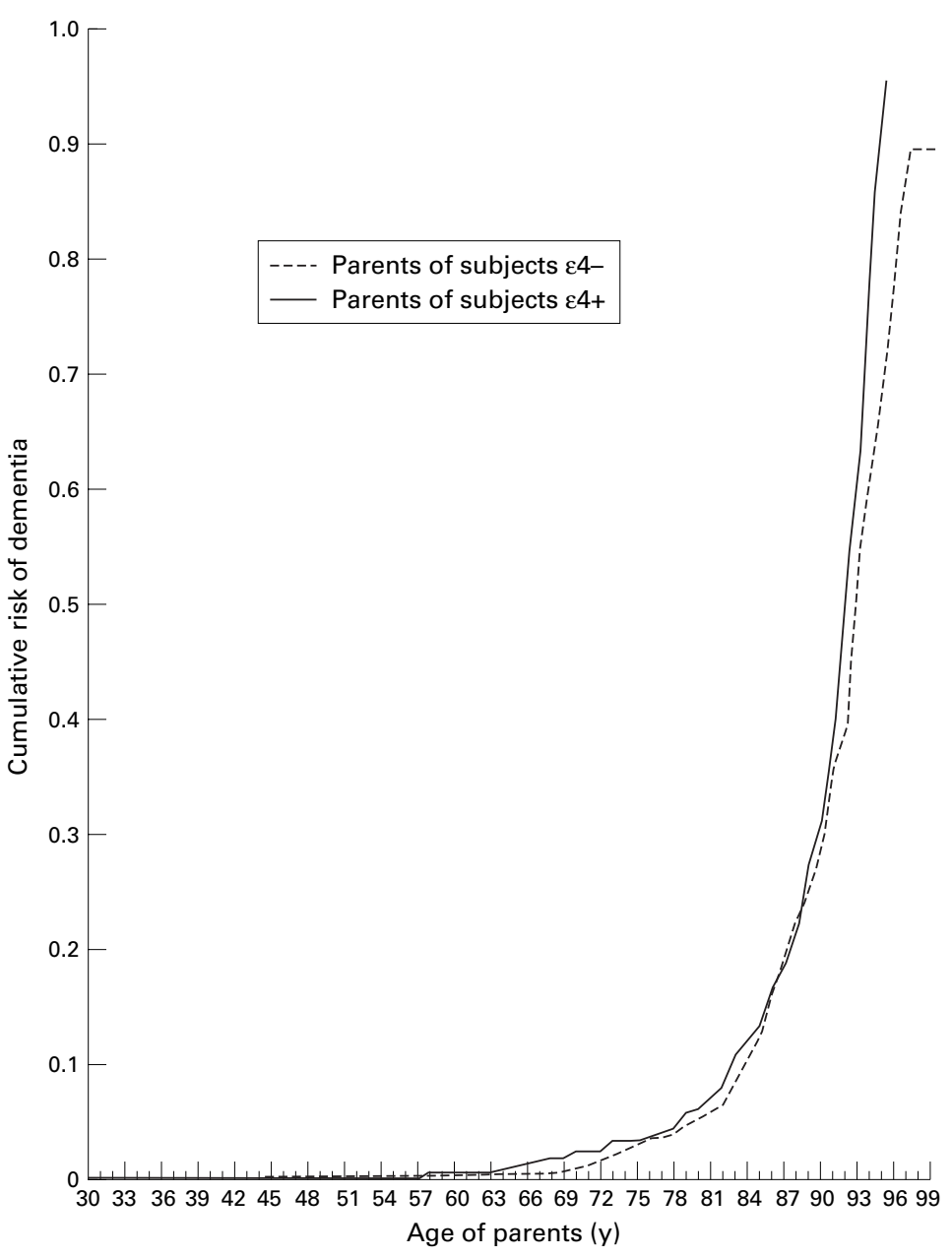

Figure 2 Cumulative risk of dementia in parents of subjects with and without the $A P O E-\varepsilon 4$ allele (using one year intervals).

score and APOE- $\varepsilon 4$ status but they had a lower educational level than probands with no missing data. Overall, $7.3 \%$ of fathers (78 of 1063) and $15.2 \%$ of mothers (167 of 1101) had dementia. Percentages of dementia increase with age in both mothers and fathers (table 3) and there is no difference between them when age is taken into account (log rank $\chi^{2}=0.46$ with $1 \mathrm{df} ; \mathrm{p}=0.49$ ).

Table 4 gives some personal and medical characteristics of parents, by sex and status for dementia. As expected, mean age for demented was significantly higher than that of nondemented, particularly in parents alive at time of inclusion. Few demented fathers were alive at time of inclusion $(n=4)$. For mothers still alive, 36 demented and 136 non-demented, the mean age of those who were demented (89.5 (3.8)) was higher than the mean age of the

Table 5 Univariate and multivariate analysis, factors associated with dementia in parents and adjusted relative risks (Cox model)

\begin{tabular}{lllllll}
\hline & \multicolumn{2}{c}{ Crude } & & \multicolumn{2}{l}{ Adjusted $^{\star}$} \\
\cline { 2 - 3 } Factors & Risk & $95 \%$ CI & & Risk & $95 \%$ CI & p Adjusted \\
\hline Parent group according to & & & & & \\
$\quad$ \&4 status of subjects & 1.22 & $0.92,1.62$ & & 1.21 & $0.90,1.63$ & 0.21 \\
Educational level & 1.64 & $1.24,2.17$ & & 1.91 & $1.43,2.55$ & $10^{-4}$ \\
History of stroke & 3.67 & $2.82,4.77$ & & 3.87 & $2.96,5.05$ & $10^{-4}$
\end{tabular}

^Adjusted for the two others factors included in the model.
Table 6 Measured risk with dilution and corresponding power of the study for expected risks varying from 1.5 to 5 (see also appendix 2)

\begin{tabular}{lll}
\hline Expected risk & $\begin{array}{l}\text { Measured risk } \\
\text { with dilution }\end{array}$ & $\begin{array}{l}\text { Power of the study } \\
\text { a posteriori (\%)t }\end{array}$ \\
\hline 5 & 3.2 & 100 \\
3 & 2.1 & 100 \\
2.5 & 1.8 & 100 \\
2 & 1.6 & 88 \\
1.5 & 1.3 & 53 \\
\hline
\end{tabular}

${ }^{\star}$ Computed for a positive predictive value of 0.60 for the questionnaire. + Calculated for each corresponding measured risk.

non-demented (87.6 (3.8); $\mathrm{p}=0.01)$. History of stroke was recorded for 2038 parents and no difference between mothers and fathers was found. Dementia in parents was associated with a history of stroke and, to a lesser extent, with a low educational level. Therefore, educational level and history of stroke were included as covariates in the multivariate analysis.

Thirteen per cent of parents of subjects having at least one $\varepsilon 4$ allele were demented compared with $10.8 \%$ of parents of subjects without this allele. Figure 2 shows the curves of cumulative risk for dementia in the two groups of parents: parents of subjects homozygous or heterozygous for APOE- $\varepsilon 4$ and parents of subjects with no $\varepsilon 4$ allele. There was no difference between these two groups of parents: the log rank test gives a $\chi^{2}=1.9$ with $1 \mathrm{df}(\mathrm{p}=0.17)$.

Table 5 gives the results of the multivariate analysis using a Cox model including group of parent according to the $\varepsilon 4$ status of subjects, educational level of parents and their history of stroke. Low educational level and history of stroke in parents were associated with an increased risk of dementia while the group of parent according to $\varepsilon 4$ allele status of subjects was not $(\mathrm{RR}=1.21 ; 95 \% \mathrm{CI}=0.90,1.63)$. The adjusted relative risks of dementia associated with an educational level below seven years of schooling and with history of stroke were 1.91 $(1.43,2.55)$ and $3.87(2.96,5.05)$, respectively.

We have also performed this analysis in the 1586 parents without history of stroke. In this subgroup, the adjusted risk of dementia in parents according to the $\varepsilon 4$ status of subjects remains non-significant $(\mathrm{RR}=1.01 ; 95 \% \mathrm{CI}=$ $0.66,1.55)$.

\section{Discussion}

The purpose of this study was to determine if rates of dementia were higher in parents of probands with at least one $\varepsilon 4$ allele than in parents of probands without this allele. In our population of 1153 volunteers with highly cognitive performing, ${ }^{26}$ the risk of dementia in parents of probands with and without the $\varepsilon 4$ allele was of 1.21 (NS). But, the probability for parents to carry at least one $\varepsilon 4$ allele was fivefold higher in parents of probands with at least one $\varepsilon 4$ allele $(p=0.59)$ than in parents of probands without this allele $(\mathrm{p}=0.12)$. Assuming that APOE- $\varepsilon 4$ allele is the major component for family history of dementia, we should find a risk of dementia in parents close to this ratio of 5 , which is independent of the 
risk of dementia according to the $\varepsilon 4$ status. This result might be related to methodological issues.

Initially, we discussed the validity of family data collected for dementia. To determine the status for dementia in parents, our information came from a single informant, while many authors in case-control studies recommend the use of a second one in family studies. Moreover, the DSMIII-R criteria used to define dementia were reported by children and not extracted from medical records. As expected with a self reported questionnaire, probands with missing data on dementia status in parents had a lower educational level than others. But some indirect arguments suggest that the quality of our data was satisfactory. Firstly, the relation between dementia and age is consistent with published data concerning both the prevalence and the incidence of dementia in various European countries. ${ }^{30-32} \mathrm{As}$ expected, we have observed an exponential increase of dementia with age, essentially doubling in rates in each decade after age 65 . Secondly, the association between dementia and low educational level is consistent with several recent studies. ${ }^{3-5}$

Differential classification bias in the detection of demented cases in parents, related to the status of probands for the $\varepsilon 4$ allele, is unlikely to come in these volunteers with highly cognitive performing. In particular, rates of probands with a score below 24 at the MMSE are not different in the two groups of probands with and without the $\varepsilon 4$ allele. On the other hand, non-differential classification bias in the detection of demented cases in parents might have caused to underestimate the measured risk. ${ }^{33}$

Lack of association might also be explained by a weak power of the study to detect an association. To take into account the probable misclassification bias on the status for dementia in measuring the risk, we have calculated in appendix 2 the dilution of the expected risk, with the formula proposed by Green; it relates the risk measured with error to the expected risk, the frequency of dementia in parents of subjects without the $\varepsilon 4$ allele and the positive predictive value (PPV) of the family history method. ${ }^{33}$ We have calculated the power a posterori with the formula proposed by Freedman in 1982 for studies using the log rank test. Thus, for an expected risk of 5, the measured risk is higher than 3 with a positive predictive value (PPV) of 0.60 for the questionnaire. In this case, the corresponding power of the study is near $100 \%$.

While an expected risk of dementia in parents at 5 is a strong hypothesis that would imply that the APOE- $\varepsilon 4$ allele explains all cases of dementia in parents, we have calculated for expected risks from 1.5 to 5 the risk measured with a PPV $=0.60$ for the questionnaire and the corresponding power a posterori for the study. Results are shown in table 6. As expected, the power of the study decreases when the risk of dementia in parents decreases. But, for an expected risk twofold higher in parents of probands with the $\varepsilon 4$ allele, the power of the study is near $88 \%$.
KEY POINTS

- APOE- 44 allele and family history of dementia are known risk factors for dementia.

- In this study, the allelic frequency for APOE- $\varepsilon 4$ was 0.12 . Parents of subjects with this allele have a fivefold higher probability to carry it than parents of subjects without this allele. Is the risk of dementia higher in parents of subjects with the APOE- $\varepsilon 4$ allele?

- We failed to demonstrate that the risk of dementia according to the $\varepsilon 4$ status of probands for this allele was significantly different of 1 .

- We discussed different biases that might interfere with this negative result. Nevertheless, we conclude that APOE- $\varepsilon 4$ can not explain a large part of family history of dementia in population.

We can therefore conclude that a history of dementia is not related to APOE- $\varepsilon 4$ status of subjects from the general population with highly cognitive performances. Moreover, while APOE- $\varepsilon 4$ cannot explain a large part of family history of dementia in the general population, others familial (genetic or environmental) risk factors for $\mathrm{AD}$ remain to be identified.

\section{Appendix 1}

Probability for parents to have at least one $\varepsilon 4$ allele according to status of subjects for APOE- $\varepsilon 4$ allele $^{20}$ :

When subjects are carriers $(\varepsilon 4 / \varepsilon 4$ or $\varepsilon 4 / \varepsilon-)$ :

$$
\begin{aligned}
& \frac{\left[\mathrm{n}(\varepsilon 4 / \varepsilon 4)^{\star} 1\right]+\left[\mathrm{n}(\varepsilon 4 / \varepsilon-)^{\star}(1+\mathrm{f})^{\star} 0.5\right]}{[\mathrm{n}(\varepsilon 4 / \varepsilon 4)+\mathrm{n}(\varepsilon 4 / \varepsilon-)]} \\
& \quad=\frac{21+245^{\star}(1+0.12)^{\star} 0.5}{266}=0.59
\end{aligned}
$$

$\mathrm{f}$ is the $\varepsilon 4$ allelic frequency in our population, $\mathrm{f}$ $=0.12$. It is also the probability for parents of subjects without the $\varepsilon 4$ allele to carry this allele.

\section{Appendix 2}

Expression of adjusted risk (RR) according to observed relative risk $\left(R R^{\star}\right)$, dementia frequency ( $f$ ) and predictive positive value (PPV) of the family method to detect dementia in parents of subjects without the $\varepsilon 4$ allele $^{33}$ : $\mathrm{RR}=\left\{\mathrm{RR}^{\star}-[(1-\mathrm{PPV}) /(1-\mathrm{f})]\right\} /\{1-[(1-$ $\mathrm{PPV}) /(1-\mathrm{f})]\}$.

or

$\mathrm{RR}^{\star}=\mathrm{RR}\{1-[(1-\mathrm{PPV}) /(1-\mathrm{f})]\}+\{(1-$ PPV) / (1 - f $)\}$.

Where $\mathrm{RR}=5, \mathrm{PPV}=0.60$, and $\mathrm{f}=0.11: \mathrm{RR}^{\star}$ $=3.21$

Frequency of dementia in parents of subjects without the $\varepsilon 4$ allele is of 0.11 in our study. For PPV, we used the result of a previous study evaluating the validity of a questionnaire sent by mail on the family history of dementia in the general population. ${ }^{34} \mathrm{~A}$ similar result $(\mathrm{PPV}=$ 0.60 ) has been found by Heun et al in a study 
conducted to evaluate the validity of the family history method for dementia in relatives of a sample of elderly subjects. ${ }^{35}$

The EVA study is carried out under an agreement between INSERM (Institut National de la Santé et de la Recherche Médicale) and the Merck, Sharp and Dhome-Chibret Laboratories (West-Point, Pennsylvania)

The authors would like to thank C Delanoe and S Bachelier for secretarial and technical support. The authors are also grateful to C Dufouil for her helpful advice.

Funding: Sandrine Danet was supported by a research gran from the FRM (Fondation pour la Recherche Médicale).

Conflicts of interest: none.

1 Ritchie K, Kildea D. Is senile dementia “ age related or ageing related ?" - Evidence from meta-analysis of dementia prevalence in the oldest old Lancet 1995;346:931-4.

2 Van Duijn CM, Clayton D, Chandra V, et al. for the Eurodem risk factors research group. Familial aggregation of Alzheimer's disease and related disorders: a collaborative re-analysis of case-control studies. Int $\mathcal{F}$ Epidemiol 1991; 20(Suppl. 2):S13-S20

3 Stern Y, Tang MX, Denaro J, et al. Increased risk of mortality in Alzheimer's disease patients with more advanced educational and occupational attainment. Ann Neurol 1995;37:590-5.

4 Bonaiuto S, Rocca WA, Lippi A, et al. Education and occupation as risk factors for dementia. A population-based pation as risk factors for dementia. A population-b
case-control study. Neuroepidemiology 1995;14:101-9.

5 Dartigues JF, Launer LJ, Andersen K, et al. The relation of Dartigues JF, Launer LJ, Andersen K, et al. The relation of
education to the risk for incident Alzheimer's Disease. education to the risk fo
Neurology 1997;48:A300.

6 Strittmatter WJ, Saunders AM, Schmechel D, et al. Apolipoprotein-E - High-avidity binding to beta-amyloid and increased frequency of type-4 allele in late-onset familial Alzheimer disease. Proc Natl Acad Sci USA 1993;90 1977-81.

7 Saunders AM, Strittmatter WJ, Schmechel D, et al. Association of apolipoprotein $\mathrm{E}$ allele e4 with late-onset familial and sporadic Alzheimer's disease. Neurology 1993;43: 1467-72.

8 Poirier J, Davignon J, Bouthillier D, et al. Apolipoprotein E polymorphism and Alzheimer's disease. Lancet 1993;342:
697-9.

9 Brousseau T, Legrain S, Berr C, et al. Confirmation of the epsilon 4 allele of the Apolipoprotein $\mathrm{E}$ gene as a risk factor for late-onset Alzheimer's disease. Neurology 1994;44:3424 .

Kuusisto J, Koivisto K, Kervinen K, et al. Association of apolipoprotein E phenotypes with late onset Alzheime

1 Chartier-Harlin MC, Parfitt M, Legrain S, et al. Apolipoprotein E e4 allele as a major risk factor for sporadic early and late-onset forms of Alzheimer's disease: analysis of the 19q13.2 chromosomal region. Hum Mol Genet 1994;3: 569-74.

12 Betard C, Robitaille Y, Gee M, et al. ApoE allele frequencies in Alzheimer's disease, Lewy body dementia, Alzheimer's disease with cerebrovascular disease and vascular dementia. Neuroreport 1994;5:1893-6.

13 Frisoni GB, Bianchetti A, Govoni S, et al. Association of Apolipoprotein E4 with vascular dementia. [Letter]. $\mathcal{F}$ Am Med Ass 1994;271:1317.

14 Hofman A, Ott A, Breteler MB, et al. Atherosclerosis, apoE, and prevalence of dementia and $\mathrm{AD}$ in the Rotterdam and prevalence of dementia

15 Slooter AJC, Tang MX, van Djuin C, et al. Apolipoprotein E $\varepsilon 4$ and the risk of dementia with stroke. F Am Med Assoc 1997;277:818-21.
16 Hardy J, Crook R, Prihar G, et al. Senile dementia of the Lewy body type has an apolipoprotein $\mathrm{E}$ epsilon 4 allele frequency intermediate between controls and Alzheimer's disease. Neurosci Lett 1994;182:1-2

17 Koller WC, Glatt SL, Hubble JP, et al. Apolipoprotein E genotypes in Parkinson's disease with and without dementia. Ann Neurol 1995;37:242-5.

18 Amouyel P, Vidal O, Launay JM, et al. The apolipoprotein E alleles as major susceptibility factors for Creutzfeldt-Jakob disease. The French research group on epidemiology of human spongiform encephalopathies. Lancet 1994;344: 1315-18.

19 Nakagawa Y, Kitamoto T, Furukawa H, et al. Allelic variation of apolipoprotein $\mathrm{E}$ in Japanese sporadic Creutzfeldt-Jakob disease patients. Neurosci Lett 1995;187: 209-11.

$20 \mathrm{Li}$ G, Silverman JM, Altstiel LD, et al. Apolipoprotein E-epsilon 4 allele and familial risk in Alzheimer's disease. Genet Epidemiol 1996;13:285-98.

21 Duara R, Barker W, Lopez-Alberola R, et al. Alzheimer's disease: interaction of apolipoprotein $\mathrm{E}$ genotype, family history of dementia, gender, education, ethnicity and age at onset. Neurology 1996;46:1575-9.

22 Van Duijn CM, de Knijff P, Cruts M, et al. Apolipoprotein E4 allele in a population-based study of early-onset Alzheimer's disease. Nat Genet 1994;7:74-8.

23 Zubenko GS, Stiffler S, Stabler S, et al. Association of the apolipoprotein E e4 allele with clinical subtypes of autopsy-confirmed Alzheimer's disease. Am f Med Genet 1994;54:199-205

24 Mayeux R, Stern Y, Ottman R, et al. The apolipoprotein epsilon 4 Allele in patients with Alzheimer's disease. Ann Neurol 1993;34:752-4

25 Payami H, Grimslid H, Oken B, et al. A prospective study of cognitive health in the elderly (Oregon brain aging study): Effects of family history and Apolipoprotein E genotype. Am f Hum Genet 1997;60:948-56.

26 Berr C, Dufouil C, Brousseau T, et al. Early effect of ApoE- $\varepsilon 4$ allele on cognitive results in a group of highly performing subjects: the EVA study. Neurosci Lett 1996; 218:9-12.

27 Hixson JE, Vernier DT. Restriction isotyping of human apolipoprotein $\mathrm{E}$ by gene amplification and cleavage with HhaI. F Lipid Res 1990;31:545-8.

28 American Psychiatric Association. Diagnostic and statistical manuel of mental disorders. 3rd ed, revised. Washington, DC: American Psychiatric Association, 1980.

29 SAS Institute, Inc. SAS user's guide, version 6.11. Cary, NC: SAS Institute, Inc, 1991.

30 Hofman A, Rocca WA, Brayne C, et al. The prevalence of dementia in Europe - A collaborative study of 1980-1990 findings. Eurodem prevalence research group. Int $\mathcal{F}$ Epidemiol 1991;20:736-48.

31 Letenneur L, Commenges D, Dartigues JF, et al. Incidence of dementia and Alzheimer's disease in elderly community residents of south-western France. Int f Epidemiol 1994;23: 1256-61.

32 Van Duijn CM. Epidemiology of the dementias: recent development and new approaches. 7 Neurol Neurosurg Psychiatry 1996;5:478-88.

33 Green MS. Use of the predictive value to adjust relative risk estimates biased by misclassification of outcome status. Am f Epidemiol 1990;43:941-7.

34 Panisset M, Fétéanu D, Berr C. Validation of a questionnaire to detect dementia cases in family. Neurobiol Aging 1992;13 (suppl 1):S117-18.

35 Heun R, Hardt J, Burkart M, et al. Validity of the family history method in relatives of gerontopsychiatric patients. Psychiatry Res 1996;62:227-38. 